\title{
Capacity building of rural women through trainings
}

\author{
ROOPA T. MALABASARI* AND UMA S. HIREMATH ${ }^{1}$ \\ Department of Extension and Communication Management, College of Rural Home Science, University \\ of Agricultural Sciences, DHARWAD (KARNATAKA) INDIA \\ ${ }^{1}$ Directorate of Extension, University of Agricultural Sciences, DHARWAD (KARNATAKA) INDIA
}

\begin{abstract}
The aim of this study is to assess the impact of KVK training programmes on knowledge and adoption of rural women about home science technologies. The present study was carried out with the sample size of 254 rural women. These rural women were categorized into two groups, i.e. trained and untrained having 127 women in each. The overall knowledge level of trained group was high in washing powder and phenyl making, maize products, mango products and bakery products. The respondents from untrained group possessed medium level of knowledge in maize products and low level in washing powder and phenyl making, mango products and bakery products. With respect to adoption, majority of trained women belonged to high level of adoption in washing powder and phenyl making, maize products, bakery products and medium level in mango products. Out of total variables cosmopoliteness in trained group exhibited significant but negative relationship with knowledge level and family income had shown positive and significant relationship with knowledge level as regard to home science technologies. Size of land holding exhibited significant but negative relationship with respect to adoption level of home science technologies. More than forty five per cent of rural women $(47.24 \%)$ stated that lack of adequate time as their main constraint in adoption of home science technologies.
\end{abstract}

KeY Words : Capacity, KVK, Programme, Rural women, Training

View Point Article : Malabasari, Roopa T. and Hiremath, Uma S. (2016). Capacity building of rural women through trainings. Internat. J. Home Sci. Extn. \& Comm. Manage., 3 (1): 8-14.

Article History : Received : 14.07.2015; Revised : 05.12.2015; Accepted : 19.12.2015

\section{INTRODUCTION}

The Indian Council of Agriculture Research (ICAR), during fifth five Year plan launched an innovative project for imparting vocational training to farmers, farm women, rural youth and field level extension functionaries in the country by establishing Krishi Vigyan Kendra (Prasad et al., 2008).

The scheme Krishi Vigyan Kendra was initiated by the Indian council of agricultural research. Women are no longer confined to their homes as house wives. Different efforts are being made by Government and other organizations for the empowerment of rural people in general and rural women in particular. KVKs play an important role for capacity building of rural women through vocational training courses. KVK is based on three main principles; agriculture production is the prime goal, second work experience as main method of

\footnotetext{
* Author for correspondence (Email: roopa2chinnu@gmail.com)
} 
imparting training and third stress on weaker sections of rural population. The KVK is a grass-root level institution designed and devoted for imparting need based skill oriented vocational training courses (Nazir et al., 2012). One of the main tasks of KVK is to provide and improve the level of knowledge of trainees about the improved farm practices (Sumathi, 2014). Hence, the present study was designed to know the capacity building of rural women through trainings with the following specific objectives:

- To find out the knowledge level of trained and untrained rural women with regard to home science technologies

- To analyze the extent of adoption of technologies by trained rural women

- To study the relationship between independent and dependent variables

- To identify the problems in adoption of imparted technologies

\section{METHODOLOGY}

The study was conducted in Bagalkot district of Karnataka state during 2014-15. A list of trainees was obtained from KVK Bagalkot who were imparted training on home science technologies. Out of six taluks of Bagalkot district, highest number of trainees were observed in Bilagi and Bagalkot taluk. From each taluk number of villages were listed and final selection of villages were made based on availability of women trained from KVK. The selected villages were Chikkasounsi, Benakatti, Bhagavati, from Bagalkot taluk; Anagwadi from Bilagi taluk. Total 254 rural women were selected for the selected 4 technologies. Out of the total sample, equal number of trained and untrained rural women were considered for each selected technology from the 4 villages i.e. 127 trained rural women who have undergone training at KVK and 127 untrained rural women from the same village were randomly selected for the study.

To study the impact of trainings on rural women 4 home science related trainings viz., washing powder and phenyl making, maize products, mango products, bakery products were selected for the study. Keeping in view the objective of the study, a structured interview schedule was prepared by reviewing the previous research studies, consulting and discussing with the home-science specialist, KVK staff and professional workers and pretested in the non-sample area. On the basis of pre-tested results, necessary modifications and changes were made in the schedule. The data was collected from trained and untrained women with the help of finalised schedule by personal interview technique in an informal atmosphere. Mean and standard deviation were used for classification of respondents into various categories. Correlation was employed to know the relationship between dependent and independent variables. To study the association between two attributes Chi-square test was used.

\section{OBSERVATION AND ASSESSMENT}

The results obtained from the present investigation are summarized below :

\section{Knowledge level of rural women about home science technologies :}

Washing powder and phenyl making :

It could be observed from the Table 1 that, majority of the trained women $(56.67 \%)$ belonged to high level of knowledge followed by medium $(23.33 \%)$ and low (20.00\%). This showed that when educational efforts by way of training were made, it might be possible to increase their knowledge (Meti, 2013 and Gautam et al., 2012).

In case of untrained group, majority of them (43.33\%) belonged to low level of knowledge (Sharma et al., 2013 and Nagnur at al., 2012) followed by medium $(40.00 \%)$ and high (16.67\%). Untrained women did not have good knowledge about washing powder and phenyl making as they did not attend the training programme. The findings of the study are similar with the findings of the Nazir et al. (2012).

The chi-square value showed highly significant association between training and knowledge level with respect to washing powder and phenyl making. The procedure and materials required for preparation of washing powder and phenyl is possible only through proper skill training and demonstration. This may be the probable reason for high association.

\section{Maize products :}

In case of preparation of maize products, it was found that more number of trained women $(48.57 \%)$ were belonged to high level of knowledge followed by low (37.14\%) and medium (14.29\%). Similar findings were reported by Dubey et al. (2008). Training also created awareness and knowledge about the nutrients of maize in keeping good health and made them to participate in 
the demonstration attentively and actively. These may be the possible reasons to have good knowledge about maize products.

More number of untrained women $(57.14 \%)$ were belonged to medium level of knowledge followed by high (22.86\%) and low $(20.00 \%)$ level of knowledge. Possibility of learning recipe from friends and neighbours may be another reason for possessing good knowledge about maize value added products. The findings of the present study are in agree with the findings of the Bala et al. (2006).

Chi-square test indicated high significant association between training and knowledge about maize products. The probable reason may be less awareness of importance of maize and its value added products by rural women.

\section{Mango products :}

The data related to knowledge level of rural women about preparation of mango products indicated that, 40.00 per cent of trained women had high level of knowledge followed by 33.33 per cent and 26.67 per cent who possessed low and medium level of knowledge, respectively. Similar findings were reported by Chauhan (2012). Possession of good knowledge might be due to appropriate training received by the women.

In case of untrained women, 36.67 per cent of them had low level of knowledge followed by 33.33 per cent and 30.00 per cent who possessed high and medium level of knowledge, respectively. Less enthusiasm to do something new products, remembering chemical names, difficulty in learning correct consisting of jam and jelly may be the reasons for low knowledge. This trend is in confirmation with the research findings conducted by Kumari et al. (2010).

Table 1 was also showed a non-significant association between training and knowledge level about mango products. Mango is one of the highly seasonal food and rural women traditionally learnt to prepare many mango products. This may be the possible reason for non-significant association between training and knowledge level.

\section{Bakery products :}

Table 1 explained knowledge level of rural women about preparation of bakery products. The results revealed that all most fifty per cent of trained women $(53.13 \%)$ had high level of knowledge followed by medium $(31.25 \%)$ and low (15.62\%). The training environment in which rural women gets more working experience through method demonstration may be the reason for having more knowledge about bakery products. The findings of the study were in conformity with the findings of Yadav and Pareek (2014).

While, 46.88 per cent of untrained women had low level of knowledge followed by medium $(31.25 \%)$ and high $(21.87 \%)$. Proper method, procedure and skills are required for the preparation of bread, cake, biscuits etc which is possible only through specific trainings may be the reason for low knowledge. Similar results were reported by Nazir et al. (2012).

It was indicated the significant association with regard to knowledge about preparation of bakery products and training. Knowledge about procedure, requirement of ingredients and equipments, baking method, how to take bakery products as an entrepreneurial activity is possible only through specific training. So this may be the reason for significant association.

\section{Adoption level of trained rural women about home science technologies :}

A close perusal of Table 2 elicits that, more number of trained women $(50.00 \%)$ belonged to high level of adoption followed by low (33.33\%) and medium (16.67\%) level category with respect to washing powder and phenyl making. Similar study reported by Kharatmol (2006). The probable reason for high adoption of this technology may be the methodology of preparation of washing powder and phenyl was found to be easy to understand because of proper guidance given to the trainees.

In case of preparation of maize products, more than fifty per cent of trained women $(51.43 \%)$ were belonged to high level of adoption followed by medium (34.28\%) and low level (14.29\%). Availability of maize in their farm and local market, easy procedure of maize recipe, taste of products liked by the family members, attending up to last stage of training programme, consuming less time for preparing, giving much importance to learn new things were the possible reasons for high adoption of maize products. The findings of the study were in conformity with the findings of Panwar et al. (2006).

The data projected in the Table 2 indicated that 80.00 per cent of trained women had medium level of adoption followed by 13.33 per cent and 6.67 per cent who possessed low and high level of adoption, respectively 
with regard to preparation of mango products. The findings of the present study agree with the findings of the Borua and Brahma (2012) and Narendra Prasad (2011). The reason for medium adoption of value added products of jam and jelly from mango is that the trained women perceive it as difficult to prepare in proper consistency and hence, showed less interest in preparation of jam and jelly. They felt mango pickling was more accepted product by family members and easy to prepare when compare to jam and jelly.

Table 2 also indicated that 50.00, 37.50 and 12.50 per cent of trained women were found in high, low and medium level of adoption category, respectively about preparation of bakery products. This may be because of proper guidance and suggestions given by KVK staffs. The findings of the present study are similar with the

\begin{tabular}{|c|c|c|c|c|c|c|}
\hline \multicolumn{6}{|c|}{ Table 1 : Knowledge level of rural women about home science technologies } & \multirow{4}{*}{$\begin{array}{c}(n=254) \\
\chi^{2}\end{array}$} \\
\hline \multirow{3}{*}{ Technology } & \multirow{3}{*}{ Knowledge level } & \multicolumn{4}{|c|}{ Respondents } & \\
\hline & & \multicolumn{2}{|c|}{ Trained $(\mathrm{n}=127)$} & \multicolumn{2}{|c|}{ Untrained $(n=127)$} & \\
\hline & & $\mathrm{F}$ & $\%$ & $\mathrm{~F}$ & $\%$ & \\
\hline \multirow[t]{5}{*}{ Washing powder and phenyl making } & Low & 06 & 20.00 & 13 & 43.33 & \\
\hline & Medium & 07 & 23.33 & 12 & 40 & $10.440 * *$ \\
\hline & High & 17 & 56.67 & 05 & 16.67 & \\
\hline & Total & 30 & 100 & 30 & 100 & \\
\hline & Low & 13 & 37.14 & 07 & 20.00 & \\
\hline \multirow[t]{3}{*}{ Preparation of maize products } & Medium & 05 & 14.29 & 20 & 57.14 & $14.040^{* *}$ \\
\hline & High & 17 & 48.57 & 08 & 22.86 & \\
\hline & Total & 35 & 100 & 35 & 100 & \\
\hline \multirow[t]{4}{*}{ Preparation of mango products } & Low & 10 & 33.33 & 11 & 36.67 & \\
\hline & Medium & 08 & 26.67 & 09 & 30.00 & $0.288^{\mathrm{NS}}$ \\
\hline & High & 12 & 40.00 & 10 & 33.33 & \\
\hline & Total & 30 & 100 & 30 & 100 & \\
\hline \multirow[t]{4}{*}{ Preparation of bakery products } & Low & 05 & 15.62 & 15 & 46.88 & \\
\hline & Medium & 10 & 31.25 & 10 & 31.25 & $9.167 *$ \\
\hline & High & 17 & 53.13 & 07 & 21.87 & \\
\hline & Total & 32 & 100 & 32 & 100 & \\
\hline
\end{tabular}

\begin{tabular}{|c|c|c|c|c|}
\hline \multirow{2}{*}{ Technology } & \multirow{2}{*}{ Adoption level } & & \multirow{2}{*}{\multicolumn{2}{|c|}{ Respondents }} \\
\hline & & & & \\
\hline \multirow{4}{*}{ Washing powder and phenyl making } & Low & & 02 & 3232 \\
\hline & Medium & & 01 & 1667 \\
\hline & High & & 03 & 50.00 \\
\hline & & Total & 06 & 100 \\
\hline \multirow[t]{4}{*}{ Preparation of maize products } & Low & & 05 & 14.29 \\
\hline & Medium & & 12 & 34.28 \\
\hline & High & & 18 & 51.43 \\
\hline & & Total & 35 & 100 \\
\hline \multirow[t]{4}{*}{ Preparation of mango products } & Low & & 04 & 13.33 \\
\hline & Medium & & 24 & 80.00 \\
\hline & High & & 02 & 06.67 \\
\hline & & Total & 30 & 100 \\
\hline \multirow[t]{4}{*}{ Preparation of bakery products } & Low & & 03 & 37.50 \\
\hline & Medium & & 01 & 12.50 \\
\hline & High & & 04 & 50.00 \\
\hline & & Total & 08 & 100 \\
\hline
\end{tabular}


findings of the Pradhan et al. (2011).

\section{Relationship between independent variables and} knowledge of the home-science technologies of trained and untrained rural women :

Table 3 indicates that out of twelve variables cosmopoliteness had shown significant but negative relationship with knowledge level. The findings of the study were not in conformity with the findings of Kharatmol (2006). It indicated that with increase of cosmopoliteness, there was decrease in the knowledge level. This may be due to the fact that only the older women were having contact with outside members than the young ones. Education and mass media participation were found to be positive but non-significant and other remaining variables were found to be non-significant and negative relationship with knowledge level of trained rural women as regard to home science technologies.

In case of untrained rural women, family income had shown positive and significant relationship with knowledge at 5 per cent level (Table 3). The findings are in consistent with the findings of Binkadakatti (2008). This indicated that with the increase of family income, the level of knowledge regarding home science technologies also increased. This may be due to the better economic condition which might have helped the respondents to participate in SHG group, trainings, meetings, extension activities etc. Other variables such as size of land holding and extension contact of untrained rural women were found to be significant at one per cent but negative relationship with respect to knowledge level. Increased land holding and extension contact resulted in decreased knowledge level with regard to home science technologies.

As land holding increases naturally women spend more time in farm related activities than training programmes. With respect to extension contact no home science specialists were visiting the villages and hence, the rural women were found to be not in contact with home science extension workers at desired level. These may be the probable reasons for negative relationship of land holding and extension contact with knowledge level. The findings of the study were in line with the findings of Sharma et al. (2013). Whereas, remaining independent variables were not having any relationship with selected dependent variable i.e. knowledge (Table $3)$.

\section{Relationship between independent variables and adoption of the home science technologies of trained rural women :}

A look at the Table 4 showed that, size of land holding exhibited significant but negative relationship with respect to adoption level about home science technologies. This showed that increased land holding resulted in decreased adoption level of home science technologies. They were found to be more interested to work in their farm related activities than home science. Their earnings from agriculture were sufficient to meet their day today requirements may also be the other reason for negative relationship with adoption level. The findings of the present study are not in accordance with

\begin{tabular}{lcc}
\hline Table 3 : Relationship between independent variables and knowledge of home-science technologies of trained and untrained rural women \\
(n=254)
\end{tabular}

12 Internat. J. Home. Sci. Extn. \& Comm. Mgmt. | Jan., 2016| Vol. 3 | Issue 1| 8-14

12 HIND INSTITUTE OF SCIENCE AND TECHNOLOGY 


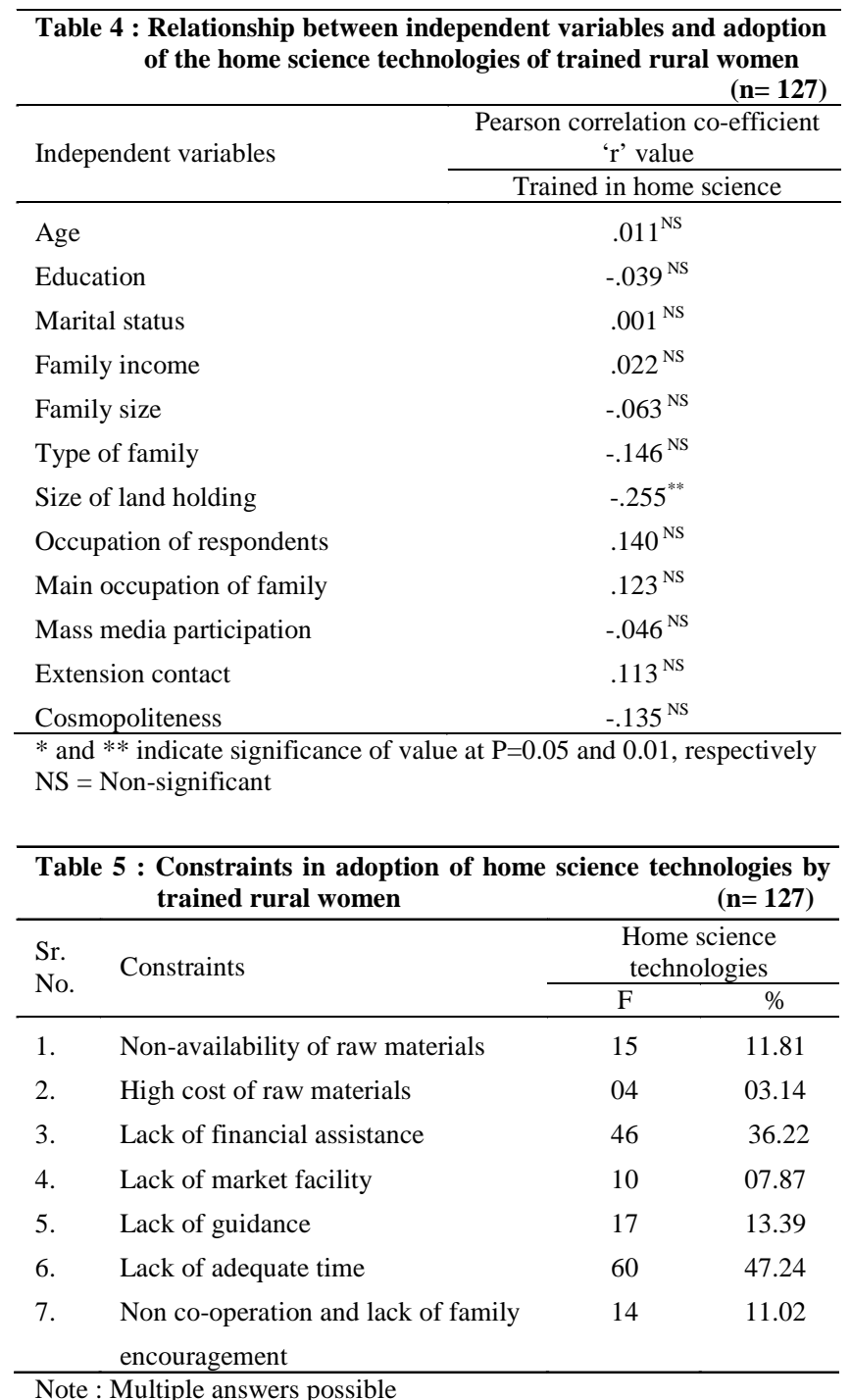

the findings of the Chandranna et al. (2008).

Education, family size, type of family, mass media participation and cosmopoliteness were found to be non significant and negative relationship and other variables showed positive and non-significant relationship with adoption level of trained rural women about home science technologies.

\section{Constraints in adoption of home science technologies by trained rural women :}

An investigation of Table 5 indicated that, majority of them stated lack of adequate time (47.24\%) as their main constraint as their main occupation of the family is agriculture and fully engaged in farm, they may not get time to practice non-farm activities followed by lack of financial assistance (36.22\%). The findings of the present study are in confirmation with the findings of the Santhi et al. (2013). Lack of guidance (13.39\%), non-availability of raw materials (11.81\%), non co-operation and lack of family encouragement (11.02\%), lack of market facility $(07.87 \%)$ and high cost of raw materials $(03.14 \%)$ were other reasons in adoption of home science technologies.

\section{Conclusion :}

The higher level of knowledge and adoption of home science technologies may be attributed due to the higher knowledge gain by the trainee. Knowledge-gain and extent of adoption by the trainees were directly proportional, as the knowledge-gain increased, the adoption of home science technologies also increased with corresponding level. Since information imparted through training programme was scientific, it was not possible for non-trainees to adopt them without going through the training programme. It may be concluded from the above results that KVK's training on home science technologies was effective in enhancing the knowledge and adoption of learnt technologies. Therefore, it could be employed that more and more such training programme in home science may be organized which would be benefited to farm women in particular and farming community in general.

\section{REFERENCES}

Bala, B., Sharma, S.D. and Sharma, R.K. (2006). Knowledge and adoption level of improved technology among rural women owing to extension programmes. Agric. Econ. Res. Rev., 19:301-310.

Binkadakatti, J.S. (2008). Impact of Krishi Vigyana Kendra trainings on use of bio-fertilizers and bio-pesticides by tur farmers in Gulbarga district. M.Sc. (Ag.) Thesis, University of Agricultural Sciences, Dharwad, KARNATAKA (INDIA).

Borua, S. and Brahma, A.K. (2012). A study on the knowledge level and extent of adoption of selected technology by rural youth trained in KVKs of AAU in Aassam. J. Acad. Indus. Res., 1(7): 374-378.

Chandranna, J.S., Jagadeeshwara, K. and Madhu Prasad, U. L. (2008). Adoption of integrated pest management practices for red headed hairy caterpillar in groundnut. Asian J. Extn. $E d u$., 37 (1 \& 2) : 35-40.

Chauhan, N.M. (2012). Knowledge level of farmers regarding package of practices for gram crop. J. Krishi Vigyan, 1 (1): 4648. 
Dubey, A.K., Srivastva, J.P., Singh, R.P. and Sharma, V.K. (2008). Impact of KVK training programme on socio-economic status and knowledge of trainees in Allahabad district. Indian Res. J. Ext. Edu., 8(2\&3): 60-61.

Gautam, S.S., Bisht, K., Sahu, B.L. and Singh, S.P. (2012). Capacity building of rural farm women through training on fruit and vegetable preservation in Tikamgarh district of Bundelkand region. A J. Multidisciplinary Adv. Res., 1(2) : 20-25.

Kharatmol, S.N. (2006). Impact of trainings conducted on vermicompost by Krishi Vigyan Kendra, Bijapur. M.Sc. (Ag.) Thesis, University of Agricultural Sciences, Dharwad, KARNATAKA (INDIA).

Kumari, M., Srivastava, A.K. and Sinha, N. (2010). Extent of knowledge of farm women on nutrition. Indian Res. J. Ext. Edu., 10 (1): 65-68.

Meti, S.K. (2013). Social and economic empowerment of farm women in agro based entrepreneurship for sustainable income. Proceeding of the International Conference on Social Science Research, 4-5 June 2013, Penang, Malaysia, p.1031.

Nagnur, S., Hosamai, V. and Shapur, A. (2012). Training on organic farming practices for women-an impact study. Karnataka J. Agric. Sci., 25 (2): 253-255.

Narendra Prasad, Verma, S.K., Singh, K.M. and Rai, M.K. (2011). To study the adoption behavior of the respondents towards the programmes of the KVKs. J. Rural Agric. Res., 11 (1):38-40

Nazir, T., Vaida, N. and Dar, M.A. (2012). Impact of Krishi Vigyana Kendras in empowerment of rural women. Researcher, 4(12) : 30-33.
Panwar, P., Gupta, P. and Rathore, N.S. (2006). Smokelesschulha an important drudgery reducing technology for farm women in Bhilwar district of Rajasthan. Indian Res. J. Extn. Edu., 6 (3): 1-4.

Pradhan, K.,Adhikary, M. M. and Biswas, T. (2011).Analyzing the extent of adoption of Integrated Pest Management approach with respect to some socio-economic attributes in Nadia district of West Bengal. J. Rural \& Agric. Res., 11(1): $41-43$

Prasad, M.S., Reddy, Y.V.R., Mayande, V.M., Ramakrishna, Y.S. and Somani, L.L. (2008). Krishi Vigyan Kendras for rural transformation. Agrotech Publishing Academy Udaipur, RAJASTHAN (INDIA).

Santhi, P., Sathyavathimuthu and Bhuvaneswari, K. (2013). Employment generating technology transfer by Krishi Vigyan Kendra as a means for empowering rural women. American Internat. J. Res. Sci. Technol., Engg. Mathematics, 2 (2) : 213219.

Sharma, P., Singh, G. P. and Jha, S.K. (2013). Impact of training programme on knowledge and adoption of preservation technologies among farm women- A comparative study. Indian Res. J. Ext. Edu., 13 (1) : 96-100.

Sumathi, P. (2014). Impact of on campus trainings conducted by the KVK, Vellore in Tamil Nadu on the knowledge level of farmers on precision farming technologies. Proceedings of the Second International Conference on Global Business, Economics, Finance and Social Sciences, 11-13 July 2014, Chennai, India, pp. 1-6

Yadav, C.M. and Pareek, O.P. (2014). Impact of on campus training on knowledge empowerment of trainees in Bhilwara district of Rajasthan. Indian Res. J. Ext. Edu., 14 (1): 122-123.

\section{$3_{\text {Year }}^{\text {rd }}$}

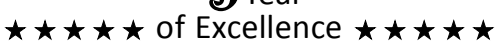

14 Internat. J. Home. Sci. Extn. \& Comm. Mgmt. | Jan., 2016 | Vol. 3 | Issue 1| 8-14 14 HIND INSTITUTE OF SCIENCE AND TECHNOLOGY 